124

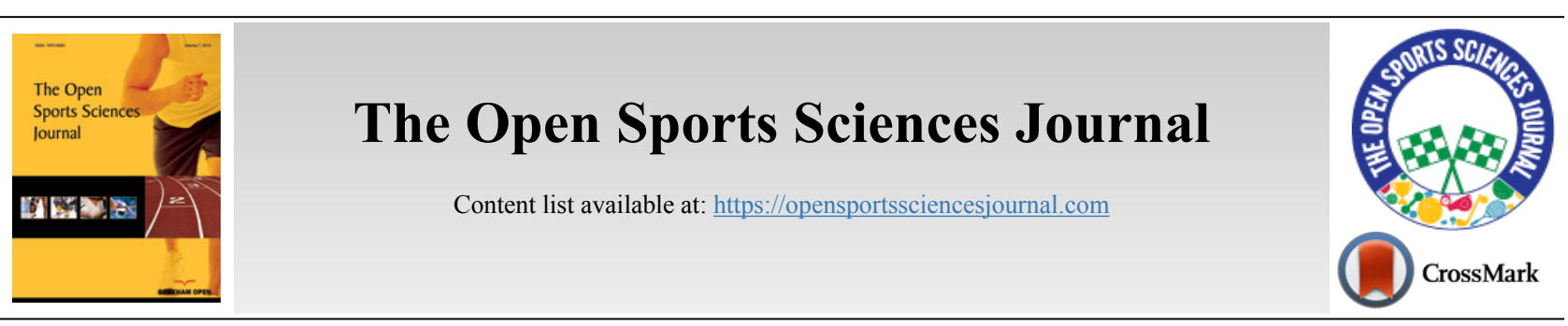

RESEARCH ARTICLE

\title{
Mineral Density and Markers of Bone Remodelling in Young Athletes in Response to Weightlifting Exercise: A Pilot Study
}

Fernando B. Reyes ${ }^{1}$, Rogelio R. Enríquez ${ }^{2}$, Julio M. Brown ${ }^{3}$, José Andre-í S. Sainz ${ }^{4}$, Rosa O. Méndez Estrada ${ }^{5}$, Rosa Consuelo V. Valle ${ }^{2}$, Armando C. Dosamantes ${ }^{3}$ and Héctor Manuel S. Sainz ${ }^{1, *}$

${ }^{\prime}$ Departamento de Ciencias del Deporte y de la Actividad Física, Universidad de Sonora, Hermosillo, Sonora, C.P. 83000, México ${ }^{2}$ Departamento de Ciencias Químico-Biológicas, Universidad de Sonora, Hermosillo, Sonora, C.P. 83000, México

${ }^{3}$ Departamento de Medicina y Ciencias de la Salud, Universidad de Sonora, Hermosillo, Sonora, C.P., 83000, México

${ }^{4}$ Departamento de Investigación en Física, Universidad de Sonora, Hermosillo, Sonora, C.P., 83000, México

${ }^{5}$ Centro de Investigación en Alimentación y Desarrollo, A. C. Hermosillo, Sonora, C.P., 83304, México

\footnotetext{
Abstract:

Background:

Weightlifting is a practice that exerts a high degree of pressure on the skeleton when supporting large loads of weight. The practice of exercise contributes by improving bone mineral density (BMD) and can prevent problems associated with low BMD.

Objective:

The objective of the present study was to determine BMD and measure bone turnover using blood markers in weightlifting athletes in response to exercise.

Methods:

The study included 16 athletes and 16 controls of both sexes in the range of 18 to 22 years old. BMD was determined at the femoral neck, hip, lumbar spine, and Total Mineral Density (TMD). The value of the total mineral density (TMDV) was obtained from the sum of the BMD of the evaluated regions. Bone formation and resorption in blood were evaluated by Alkaline Phosphatase (ALP) and Acid Phosphatase (ACP), respectively. In addition, the concentration of urea and Creatine Kinase (CK) were determined.

Results:

The mean BMD of the lumbar spine and TMDV was of $1.2 \mathrm{~g} / \mathrm{cm}^{2}$ in female and male athletes. In young people who did not practice weightlifting, BMD in the lumbar spine $\left(0.9 \mathrm{~g} / \mathrm{cm}^{2}\right.$ in both groups) and TMDV $\left(1.05 \mathrm{~g} / \mathrm{cm}^{2}\right.$ in women and $1.11 \mathrm{~g} / \mathrm{cm}^{2}$ in men) were significantly lower $(p<0.05)$. The activity in bone formation and $\mathrm{CK}$ in male athletes was twice as high compared to the other groups. The blood urea concentration in athletes (32.7- $38.0 \mathrm{mg} / \mathrm{dL})$ was significantly higher $(p<0.05)$ compared to the control groups $(19.3-18.8 \mathrm{mg} / \mathrm{dL})$.

\section{Conclusion:}

The practice of weightlifting benefits bone mass gain in the lumbar spine. These findings suggest that exercises in which high weight loads are supported promote bone turnover and mineralization to prevent bone weakening.
}

Keywords: Bone mass, Dual-energy X-ray absorptiometry, Markers of bone turnover, Alkaline phosphatase, Acid phosphatase, Weights exercise.

Article History Received: February 7, 2021

Revised: September 27, 2021 Accepted: September 29, 2021

\section{INTRODUCTION}

Weightlifting is one of the practices that most involves the development of physical strength and power $[1,2]$. During the

\footnotetext{
* Address correspondence to this author at the Departamento de Ciencias del Deporte y de la Actividad Física, Universidad de Sonora, Rosales y Blvd. Luis Encinas, P.O. Box 1658, C.P. 83000, Hermosillo, Sonora, México;

Tel: (662) 454-8418; E-mail: hsarabiasainz@gmail.com
}

performance of weightlifting, a constant pulling force is experienced on the muscles and bone tissue. Several studies with weightlifting athletes have studied strength development, muscle mass gain, or the influence of diet in sports performance [3 - 5]. Exercising with weights benefits cardiovascular health, joint function, mental health, and body composition. Probably one of the most important benefits of 
strength exercises is the promotion of ontogenesis [6].

On the other hand, osteoporosis is an age-related disease characterized by low mineralization of the bones. With aging, some processes such as the decrease in the activity of the osteoblasts mandated for bone mineralization and the increase in the osteoclasts responsible for bone degradation cause an unfavorable imbalance for bone mineralization [7]. Physical activity is essential for the correct development of the bone since the architecture and bone mass depend on the degree of pressure of the biomechanical load of the exercise [8]. Not practicing impact exercises on the bones can affect bone density and structure. Consequently, there is a weakening of the bones due to the increase in microfractures, which can lead to the development of osteoporosis [9].

The influence of exercise on bone mineral density has been addressed in several studies. Marques et al. [10] evaluated the effects of weight-bearing exercise on BMD in older women, suggesting that training with moderate impact on the bones reduces the risk of fractures. Shah et al. [11] reported that a diet focused on weight loss accompanied by physical training prevents increased bone turnover and attenuates the loss of bone density in obese older adults. While Bolam et al. [12], conducted a systematic review of nine trials conducted in middle-aged and older men to determine the effect of weightbearing and resistance exercises on BMD. The reviewers found that weight-bearing activities and resistance training can be considered as a preventive strategy for osteoporosis.

Exposure to exercises with mechanical stress on the bones can have osteogenic effects. One of the hypotheses put forward by the authors is that the impact on the bones produces microfractures, activating the bone surface by the retraction of the limiting cells (osteoblasts) [13]. Subsequently, the exposed membrane is digested by the action of collagenases. As the mineralized surface is exposed, the attraction of circulating osteoclasts is produced to give way to mineralization until the cavity is completely filled with an osteoid substance. The entire process involving bone mineralization ends in approximately 130 days [13].

Although osteoporosis is more common in older adults, it can occur at an early age if risk factors related to lifestyle are not considered. The young population is uninformed and unprotected in terms of its prevention. The main factors that contribute to the development of bone mass are the level of its maximum gain until adolescence and the rate of loss due to aging. Reaching peak bone mass with the help of exercise can provide protection as resorption occurs with age [14]. Weight bearing impact activities should be considered as a strategy to prevent osteoporosis [12]. Exercises that involve strength development have been reported to increase bone mass [15]. Weightlifting is a sport that provides a high degree of pressure on the skeleton and can help to achieve peak bone density values.

Dual-energy X-ray absorptiometry (DXA) is a technique used to determine bone mineral density. The diagnosis of osteoporosis is made by this method. In sports clinical practice this technique has been used to evaluate bone mineralization in athletes who practice low and high-impact sports [16]. The ability of this method to detect even minimal changes in skeletal muscle mass in populations of patients with cirrhosis and sarcopenia has been reported [17 - 19]. In the present study, this technique was used to assess BMD and muscle mass in weightlifting athletes. The studies were accompanied by the analysis of biomarkers in the blood associated with bone turnover and muscle metabolism. The aim of the study was to determine BMD and measure bone turnover in weightlifting athletes in response to weight-bearing impact exercise.

\section{MATERIALS AND METHODS}

\subsection{Subjects}

The study included 16 athletes (eight women and eight men) between 18 and 22 years old, recruited from the representative weightlifting team from the University of Sonora, Mexico. The control group consisted of eight men and eight women of the same age range. All were college students who did not practice weightlifting as physical activity. Three of the athletes (two women and one man) did not complete the study because they did not meet the study protocol or the inclusion criteria mentioned below. The athletes had a minimum of one year of training. Participants were matched for age and sex and divided into four groups: female athletes (FA), non-female athletes (NFA), male athletes (MA), and non-male athletes (NMA). All were in good health and reported not being under medical treatment, in addition to having your voluntarily signed informed consent. To carry out the study, the ethical considerations of the Helsinki Declaration of the World Medical Association were taken into account and the approval of the Ethics Committee of the University of Sonora.

\subsection{Anthropometric Characterization and Feeding}

Prior to the BMD evaluation, the participants were characterized by weight and height with an electronic scale equipped with a Tanita brand stadiometer (TBF-410GS, Arlington Heights, USA). The body mass index (BMI) was calculated as the ratio of weight $/ \mathrm{height}^{2}\left(\mathrm{~kg} / \mathrm{m}^{2}\right)$. Participants completed a questionnaire related to their eating behavior and history of physical activity. The evaluation of feeding behaviors was performed using the Eating Attitudes Test (EAT-26) [20]. The daily food intake was calculated using the Diet History Questionnaire (DHQ II) of the National Cancer Institute (NCI), from which the intake of calories (Kcal) and calcium $(\mathrm{mg})$ were obtained with the help of the software Diet * Calc for PC. For its application, some modifications were made to the list to ensure the inclusion of the main contributors of food for Hispanics. For the exclusion criteria, participants with an EAT score greater than 20 were discarded, as well as subjects with chronic diseases such as diabetes (type 1, 2 or gestational), hypo or hyperthyroidism, or kidney failure, and recurrent users of alcohol (more than 35 gr per week), tobacco, or anabolic steroids.

\subsection{Training Evaluation}

Prior to the BMD evaluation, all participants answered a training history questionnaire. The athletes had a previous year of preparation for their annual college competition. The 
training programme was assigned by the coach with routines of two hours a day, five days a week (Table 1). Each athlete worked with weight loads according to his or her physical abilities. The subjects of the control group were young people from the university's population who did not practice weightlifting nor had any assigned training. The subjects reported not being sedentary, as they carried out daily activities such as walking or cycling to school, working in restaurants, cleaning the home, or travelling in public transport. No subject in the control group practiced demanding exercises such as cycling, tennis, running, vigorous walking, or performing heavy work such as mowing or carrying loads.

\subsection{Total Daily Energy Requirements}

To determine if the calorie consumption of the subjects was in accordance with their daily energy needs, the total energy expenditure (TEE) was calculated. According to the method proposed by $\mathrm{FAO} / \mathrm{WHO} / \mathrm{UNU}$ [21], to calculate the $\mathrm{Kcal} /$ day of resting energy expenditure (REE) in 18-30-yearolds, the following equations were used: $12.2 *$ weight +496 in women; $15.3 *$ weight +679 in men. Subsequently, the REE is multiplied by the corresponding physical activity factor: mild (REE * 1.5 in women and REE * 1.6 in men); moderate (REE $* 1.6$ in women and $\mathrm{REE} * 1.7$ in men); intense (REE * 1.9 in women and $\mathrm{REE} * 2.1$ in men) [22].

\subsection{Protocol}

Analyses were performed two weeks before the end of the training season for the annual university competition. The volunteers arrived at the evaluation facility between 8 and 11 in the morning for blood collection and BMD evaluation. Control group subjects were also evaluated in this period. Blood sampling was performed by venipuncture from the ante-ulnar region of the fasting arm. The blood was collected in plastic BD Vacutainer ${ }^{\circledR}$ serum tubes and transported to the laboratory while maintaining a temperature of $4{ }^{\circ} \mathrm{C}$. Subsequently, the serum was separated by centrifugation at $3,000 \mathrm{rpm}$ for $15 \mathrm{~min}$ and stored at $-80^{\circ} \mathrm{C}$ for biochemical analysis.

\subsection{Evaluation of Bone Mineral Density}

$\mathrm{BMD}$, percent body fat $(\% \mathrm{BF})$, and percent fat-free mass (\% FFM) were obtained from densitometry analysis on a QDR Hologic Discovery A device (Hologic, Inc. Bedford, MA, USA). The measurement was carried out wearing minimum clothing with a shirt and shorts. To obtain the measurement of the lumbar spine, the subjects were placed in a supine position with their knees bent at a $90^{\circ}$ angle. To measure the hip, the subjects were placed supine with the left hip abducted inwardturned at a $45^{\circ}$ angle. The full-body scan started with the upper right part of the body, followed by the central part and, finally, the left part. The BMD of the femoral neck, lumbar spine, and hip and total mineral density (TMD) were determined. Likewise, images of various anatomical points were selected to obtain the content of fat mass and fat-free mass. For the interpretation of the results in $\mathrm{Z}$ values, an adjustment for age, sex, weight, height, and ethnicity was performed.

\subsection{Biochemical Analysis}

A Microlab 300 clinical chemistry analyser (RANDOX, USA) was used for the quantification of ALP, ACP, urea, and CK. All trials were performed using RANDOX Reagents (USA) test kits following the supplier's directions. The pipetting scheme was established at $25^{\circ} \mathrm{C}$ for the enzymatic reactions according to the indications of the kit. Each test was performed in triplicate with a coefficient of variation $<2 \%$. The enzymatic concentrations were expressed in units per litre $(\mathrm{U} / \mathrm{L})$, while the urea concentration was expressed in $\mathrm{mg} / \mathrm{dL}$.

\subsection{Statistical Analysis}

Values were reported as medians \pm standard deviations. The Anderson-Darling test was applied to determine the normality of the data. Since these did not have a normal distribution, non-parametric tests were applied. For the group comparison of the descriptive data, the Kruskal-Wallis test was applied. Subsequently, a pairwise comparison was performed using the Mann-Whitney test with Bonferroni significance adjustment. A gradual regression was performed to determine if weight, $\mathrm{BMI}, \% \mathrm{FFM}, \% \mathrm{BF}$, daily energy consumption, daily calcium intake were associated with the BMD of each anatomical region evaluated. All covariates were found to be associated with BMD in any anatomical region. However, although the regression model does not depend on the normality of the data, no conclusions can be drawn about the coefficients because all the variables were highly correlated. The value of the total mineral density (TBMD) was included in the analysis, which was calculated by adding the four anatomical regions analyzed. All analyzes were performed at a $95 \%$ confidence level $(p<0.05)$. For the statistical analysis, the statistical software SAS 6.08 from PCS was used.

\section{RESULTS AND DISCUSSION}

The anthropometric characteristics and nutrient intake of each group are shown in Table $\mathbf{2}$. The average age was similar among the participants, with a range of 18 to 22 years. Weight and height were significantly higher in men than in women, with no significant differences between groups of the same sex. The BMI was 19 to 25 (normal weight), without significant differences between groups. The $\% \mathrm{BF}$ in the group of MA was significantly lower compared to the other study groups, with values ranging from $8 \%$ to $19 \%$, which is considered healthy. No significant differences were observed between the rest of the evaluated groups. The \%FFM was similar between groups of the same gender, however, the males showed a significantly higher $(p<0.05)$ percentage regarding both groups of women. Calorie consumption was higher in men than in women, without significant differences between groups of the same gender. The calculation of the daily energy requirements indicated that in the MA group the caloric needs were higher compared to the NMA group and this, in turn, was higher than both groups of women, in which the energy needs were similar. According to the estimation of calcium consumption in the diet, this was similar in all the evaluated groups.

According to the International Osteoporosis Foundation (IOF), young people who have a BMI of less than $20 \mathrm{~kg} / \mathrm{m}^{2}$ are at greater risk of suffering a fracture. In the present study, no 
participant presented low BMD (Z-score values below -2.0 to -2.9 SE) even though two women in the control group showed a BMI lower than recommended. This is relevant, given that low body weight is associated with low bone mass [23] and an increased risk of fractures [24]. Usually, there is a relationship between \%BF and BMI. If there is a high BMI, it is because there is a large amount of body fat, except in the case of athletes, where the proportion of muscle mass is usually higher than in non-athletes. In this study, the \%FFM was similar between athletes and non-athletes but different between genders. However, the \%BF was significantly lower $(p<0.05)$ in male athletes, indicating a higher proportion of lean mass (bones, vital organs, and muscles mainly) in the subjects of this group. Although there were no significant differences in BMI between groups, it is important to consider body composition, since in young athletes, it has been suggested that muscle mass gain is positively associated with bone mass gain and vice versa [25]. Therefore, it is highly recommended to increase muscle mass through exercise to promote bone density gain during youth.

Regarding the level of activity, according to the physical activity questionnaire, non-athlete women and men had a mild level of activity. Their daily activities were walking, working in a restaurant, cleaning the house, taking care of children, traveling by bus or car. None of them claimed to practice some sport. While the activity level of the athletes was intense with two hours of daily exercise. In the case of the FA and MA groups, their calorie intake was below their energy needs. In the NFA and NMA groups, energy consumption and the energy expenditure calculated for your level of physical activity were similar. However, it was detected that some men in the control group $(n=4)$ showed a higher consumption than recommended for their level of physical activity and a BMI greater than 25 (overweight). Two women in the NFA group consumed fewer calories than those calculated for their daily energy needs. Among the main risk factors that influence a low BMD are a sex and poor diet. Also, if the intake of calcium and vitamin D is deficient, together with low body weight, the risk of suffering bone fractures is greater even at an early age [26].

Regarding the calcium intake, the range of daily consumption was between 920-1250 mg without significant differences between groups $(p<0.05)$. It is stated that in young people over 18 years of age, intake should be greater than $1,000 \mathrm{mg}$ per day [27]. Calcium is one of the essential nutrients for the development of bone mass. In young women, it has been reported that there is a positive relationship between calcium intake and bone mass gain in the radius, lumbar spine, and hips [28, 29]. Nutrition is a modifiable factor, and it is clear that calcium intake in the study population can be improved. However, in addition to taking care of the dietary intake of calcium, the IOF recommends $40 \mathrm{~min}$ of daily exercise with a moderate or intense impact on the bones, such as jumping, dancing, or running, to promote the development of bone mass.

Fig. (1) shows the BMD of the femoral neck, hip, lumbar spine and TMD of each group. The BMD of the femoral neck was similar between the FA, MA and NMA groups but significantly lower ( $p$ 0.05) in the NFA group. At the hip, the BMD in NFA was significantly lower with respect to that detected in male athletes. The lumbar spine bone mass in male and female athletes was significantly higher $(p<0.05)$ compared to people who did not practice weightlifting. However, there were no significant differences in the TMD between the groups evaluated.

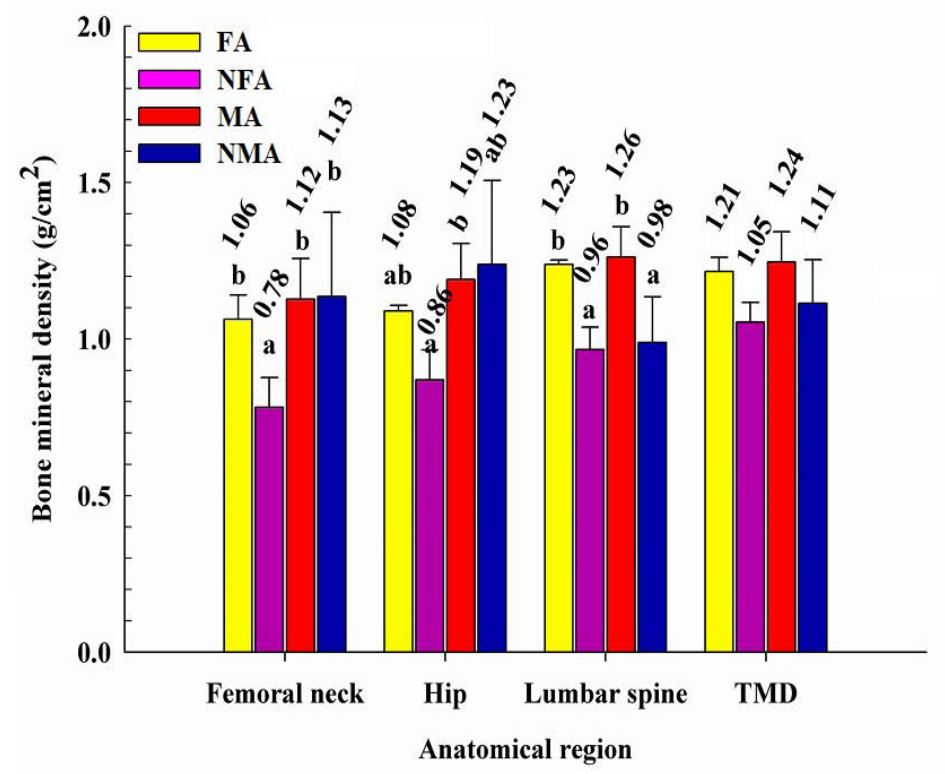

Fig. (1). Bone mineral density in the femoral neck, hip, lumbar spine and total mineral density (TMD) in young non-athletes and weightlifting athletes. Female athletes (FA), non-female athletes (NFA), male athletes (MA), and non-male athletes (NMA). Different letter indicates significant differences between groups in each anatomical region according to the Kruskal-Wallis test and the Mann-Whitney comparison of medians $(p<0.05)$. 


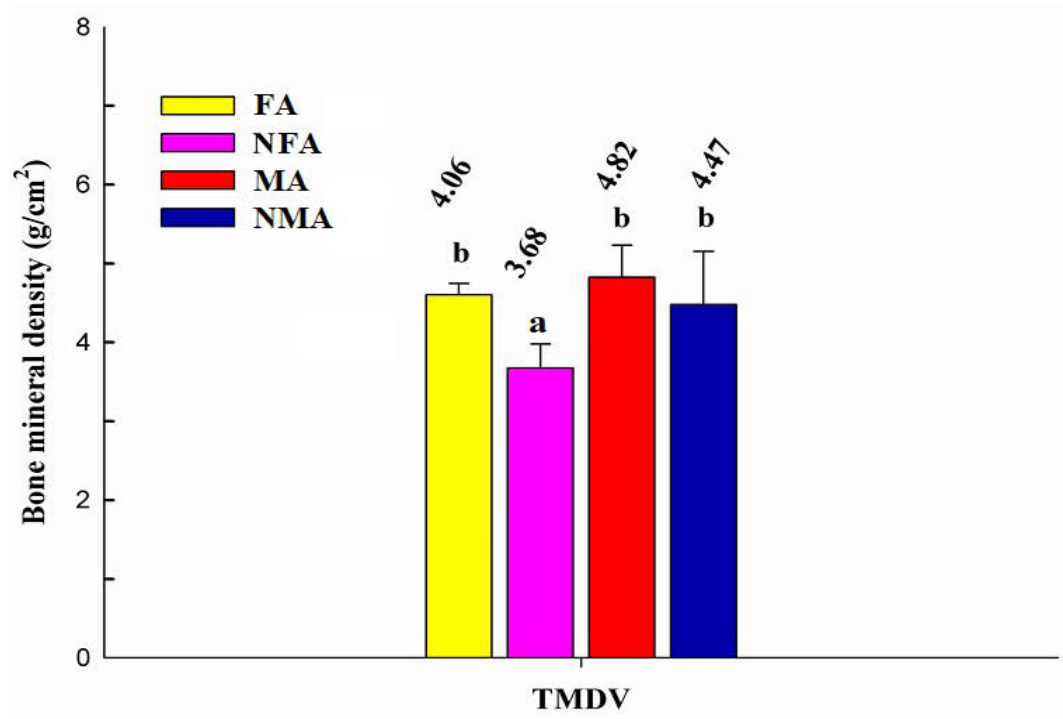

Anatomical region

Fig. (2). Total mineral density value (TMDV) in young non-athletes and weightlifting athletes. Female athletes (FA), non-female athletes (NFA), male athletes (MA), and non-male athletes (NMA). Different letter indicates significant differences between groups in each anatomical region according to the Kruskal-Wallis test and the Mann-Whitney comparison of medians $(p<0.05)$.

The weight load experienced during weightlifting practice seems to impact mainly the lower back. The spine has the functions of keeping the body upright and supporting and transmitting the weight of the head, upper extremities, and trunk to the legs. It has been reported that when performing barbell half squats, lifting loads from 0.8 to 1.6 times of body weight, the compression acting on the lumbar spine (L3-L4) increases from 6 to 10 times [30]. Likewise, the BMD of the hip and the femoral neck in women who practiced weightlifting turned out to be benefited, when detecting similar values to those observed in males. This is interesting since hip and vertebra fractures are among the most common in older people, mainly in women [ $31-33]$. It has been estimated that $30 \%$ of older adults will experience a fall during their lifetime, and $15 \%$ will result in a fracture. The hip is one of the regions of most concern due to its disabling and lethal consequence in $50 \%$ of cases after surgery $[24,34]$. By the time weightlifting athletes finish their stage as college athletes, it is highly likely that they will achieve a maximum peak of bone mass in these areas, protecting them from future injuries due to lack of bone mineralization.

The total mineral density value of each group was obtained with the sum of the average BMD of each anatomical region evaluated. Fig. (2) shows the TMDV in each group. No statistical differences were detected between female athletes and both groups of males. However, in women who did not practice weightlifting, the TMDV was significantly lower $(p<$ 0.05 ). The architecture and bone mass of the bone depending on the degree of pressure of the workload with which it is trained [25]. In this case, it seems that in women who were under training, the stress to which the bones were subjected by weight loads helped promote osteogenesis in certain areas, reaching a higher average TMDV compared to non-athlete women. A study by Creighton et al. [16] in university women revealed that players of volleyball and basketball, considered high-impact sports, had higher BMD in the femoral neck and trochanter and TMDV compared to players of soccer and swimming, sports considered medium and low impact, respectively. However, no difference in spine BMD density was detected among this group of women. On the contrary, according to our results, weightlifting practice contributed to the mineralization of the lumbar in men and women and helped increase TMDV in women. In this sense, it seems that each sport impacts different areas of the skeleton, contributing to its mineralization.

Table 3 shows the blood values of the markers of bone formation and resorption. The objective of evaluating biomarkers of bone remodelling is to study the influence of exercise on metabolism and dynamic turnover in bone. The ALP activity was significantly higher $(p<0.05)$ in the group of male athletes compared to the other study groups, which did not differ from each other. This enzyme plays a very important role in mineralization and osteoid formation. No significant differences in the ACP activity were detected between the groups. Its concentration in the blood is a marker of osteoclast activity and bone resorption $[35,36]$.

Tracking markers of bone remodelling are analyses that generally accompany studies of BMD in athletes. Matsumoto et al. [37] reported a higher activity in bone resorption in judokas compared to runners and swimmers. Resorption was determined by urinary pyridinoline and deoxypyridinoline. However, no significant differences were reported in terms of bone formation as measured by the activity of the ALP and the procollagen type I carboxy-terminal propeptide (PICP). 
Table 1. Weekly training routine of the weightlifting athletes.

\begin{tabular}{|c|c|c|c|c|}
\hline Monday & Tuesday & Wednesday & Thursday \\
\hline Barbell squat $(4 \times 5)$ & Barbell squat $(4 \times 5)$ & $\begin{array}{c}\text { Barbell squat with maximum } \\
\text { weight }(1 \times 10)\end{array}$ & $\begin{array}{c}\text { Barbell squat with maximum } \\
\text { weight }(3 \times 3,1 \times 5)\end{array}$ & $\begin{array}{c}\text { Snatch maximum weight } \\
(10 \times 1)\end{array}$ \\
\hline Snatch $(5 \times 3)$ & Snatch push press $(3 \times 10)$ & Jerk $(5 \times 2)$ & Snatch balance $(3 \times 3)$ \\
\hline Cuban press $(3 \times 3)$ & Clean $(5 \times 2)$ & Pull snatch $(3 \times 3)$ & Jerk pull $(3 \times 3)$ \\
\hline Barbell shrug $(4 \times 5)$ & Jerk pull $(3 \times 3)$ & Dead-weight $(5 \times 4)$ & Split jerk $(5 \times 2)$ & Run $(40$ min) \\
\hline
\end{tabular}

The number of series per repetitions performed in each exercise is indicated in parentheses.

Table 2. Anthropometric characteristics and nutrient intake per day in young athletes and non-athletes.

\begin{tabular}{|c|c|c|c|c|}
\hline Variables & Female Athletes $(\boldsymbol{n}=\mathbf{6})$ & Non-Female Athletes $(\boldsymbol{n}=\mathbf{8})$ & Male Athletes $(\boldsymbol{n}=7)$ & Non-Male Athletes $(\boldsymbol{n}=\mathbf{8})$ \\
\hline Age (yr) & $20 \pm 0.7$ & $19.1 \pm 0.3$ & $20 \pm 1.5$ \\
\hline Height (cm) & $160.04 \pm 5.16^{\mathrm{a}}$ & $161.09 \pm 5.01^{\mathrm{a}}$ & $174.16 \pm 3.10^{\mathrm{b}}$ & $176.82 \pm 6.14^{\mathrm{b}}$ \\
\hline Weight (kg) & $56.80 \pm 6.85^{\mathrm{a}}$ & $55.70 \pm 5.8^{\mathrm{a}}$ & $78.50 \pm 9.2^{\mathrm{b}}$ & $82.10 \pm 5.17^{\mathrm{b}}$ \\
\hline Body mass index & $22.95 \pm 1.83$ & $21.10 \pm 2.11$ & $23.50 \pm 2.76$ & $16.95 \pm 3.40^{\mathrm{a}}$ \\
\hline Percent body fat (\%) & $27.45 \pm 3.53$ & $24.39 \pm 4.02$ & $29.90 \pm 6.02$ \\
\hline Percent fat-free mass (\%) & $73.69 \pm 6.41$ & $74.61 \pm 1.67$ & $82.18 \pm 8.17 .19^{\mathrm{b}}$ & $79.33 \pm 8.30^{\mathrm{b}}$ \\
\hline Daily energy consumption (Kcal) & $2187.74 \pm 185.01$ & $1923 \pm 108.04$ & $3196 \pm 450.26^{\mathrm{b}}$ & $3173.19 \pm 325.62^{\mathrm{b}}$ \\
\hline Daily energy requirement (Kcal) & $2316.39 \pm 183.12$ & $1776.42 \pm 109.55$ & $3908.47 \pm 556.73^{\mathrm{b}}$ & $3096.19 \pm 423.0^{\text {bc }}$ \\
\hline Calcium (m) & $920 \pm 161$ & $890 \pm 135$ & $1250 \pm 260$ & $1190 \pm 382$ \\
\hline
\end{tabular}

Values are medians \pm standard deviations. ${ }^{a}$ indicates significant differences compared to the other study groups, ${ }^{b}$ indicates significant differences compared to the female groups, ${ }^{\mathrm{c}}$ indicates significant differences between male and non-male athlete groups according to the Kruskal-Wallis test and the Mann-Whitney comparison of medians $(\mathrm{p}<0.05)$. Number of subjects $(n)$.

Table 3. Blood markers of bone remodeling and muscle degradation in young non-athletes and weightlifting athletes.

\begin{tabular}{|c|c|c|c|c|}
\hline Variables & Female Athletes $(\boldsymbol{n}=\mathbf{6})$ & Non-Female Athletes $(\boldsymbol{n}=\mathbf{8})$ & Male Athletes $(\boldsymbol{n}=\mathbf{7})$ & Non- Male Athletes $(\boldsymbol{n}=\mathbf{8})$ \\
\hline Alkaline phosphatase (U/L) & $114.91 \pm 44.27$ & $97.83 \pm 27.09$ & $227.9 \pm 65.20^{\mathrm{a}}$ & $95.0 \pm 40.21$ \\
\hline Acid phosphatase (U/L) & $2.82 \pm 2.12$ & $1.06 \pm 0.82$ & $4.27 \pm 2.16$ & $2.81 \pm 1.14$ \\
\hline Urea (mg/dL) & $32.73 \pm 4.88$ & $19.33 \pm 6.71^{\mathrm{d}}$ & $38.71 \pm 9.50$ & $18.80 \pm 4.60^{\mathrm{c}}$ \\
\hline Creatine kinase (U/L) & $126.51 \pm 64.10$ & $45.33 \pm 20.26$ & $322.26 \pm 74.05^{\mathrm{a}}$ & $135.75 \pm 73.98$ \\
\hline
\end{tabular}

Values are means \pm standard deviations. ${ }^{a}$ indicates significant differences compared to the other study groups, ${ }^{\circ}$ indicates significant differences between male and nonmale athlete groups, ${ }^{\text {d }}$ indicates significant differences between female and non-female athlete groups according to the Kruskal-Wallis test and the Mann-Whitney comparison of medians $(p<0.05)$. Number of subjects $(n)$.

Likewise, Creighton et al. [16] evaluated bone synthesis and degradation from the concentration of PICP and carboxyterminal telopeptide of type I collagen (ICTP), respectively, without finding significant differences in bone metabolism in young women who practiced different sports. One of the limitations of the use of markers of bone metabolism is the variation in concentration during the day. To decrease this factor, in the present study, all blood samples were collected in the morning on an empty stomach during the same period. Our results indicate greater activity in bone formation in men who practiced weightlifting. Despite some limitations, the quantification of bone markers is of great value in the diagnosis of bone formation and resorption in athletes to determine their bone metabolism.

In athletes under training, the concentration of some markers in the blood may increase as a result of exercise. Blood urea analyses showed a higher concentration in women and men who practiced weightlifting (Table 3). Urea is a breakdown product of muscle metabolism and is indicative of the amount of protein catabolised. Monitoring their blood levels is a good parameter of training load [38]. Strenuous exercise over short periods produces a slight increase in urea concentration [38]. It has been proposed that the acute phase of urea in the post-exercise stage determines the magnitude of the training load. Thus, a training session would have been adequate if it elicits a response in increasing urea levels in the post-exercise phase [39]. Likewise, CK activity was higher in the MA group with respect to the other three evaluated groups, which did not show significant differences between them (Table 3). In individuals who regularly engage in intense exercise, CK levels are usually significantly higher compared to sedentary or moderately active people [40]. The lower concentration detected in the FA group may be due to the secretion of estradiol, a female estrogenic hormone that limits the release of CK. Despite its mitigating effect on CK release, it is not directly related to less muscle damage from exercise [41]. Some authors state that serum CK levels may be an indicator of damage to muscle tissue in response to the magnitude of exercise load $[42,43]$. The analyses of their concentration in the blood after exercise could help determine 
the threshold of load or physical activity necessary to stimulate bone remodelling.

\section{CONCLUSION}

Findings from this study indicate that weightlifting increases bone mass gain in the lumbar vertebrae. In women, the practice of weightlifting improved the mineral density of the femoral neck and lower back, increasing the value of total mineral density compared to the population of non-athlete women in this study. Weight training in men increased alkaline phosphatase activity and creatine kinase, parameters related to bone formation and muscle protein turnover. Blood urea concentration values of weightlifting athletes were higher than in inactive subjects. These results reaffirm the theory that activities where the skeleton is subjected to weight-bearing induce bone formation and help improve mineral density. More research is needed to confirm and expand on these results.

\section{ETHICS APPROVAL AND CONSENT TO PARTICIPATE}

This study has been approved by the Ethics Committee of the University of Sonora, Mexico.

\section{HUMAN AND ANIMAL RIGHTS}

No animals were used in this research. All human research procedures were followed in accordance with the ethical standards of the committee responsible for human experimentation (institutional and national) and with the Helsinki Declaration of 1975, as revised in 2013.

\section{CONSENT FOR PUBLICATION}

Informed consent was obtained from the participants.

\section{STANDARDS OF REPORTING}

STROBE guidelines were used in this study.

\section{AVAILABILITY OF DATA AND MATERIALS}

Not applicable.

\section{FUNDING}

We thank the Department of Sports Sciences and Physical Activity of the University of Sonora for their financial assistance to carry out this work and CONACYT for the support of Basic Scientific Research Project No. 41029.

\section{CONFLICT OF INTEREST}

The authors declare no conflict of interest, financial or otherwise.

\section{ACKNOWLEDGEMENTS}

Declared none.

\section{REFERENCES}

[1] Hermassi S, Chelly MS, Tabka Z, Shephard RJ, Chamari K. Effects of 8 -week in-season upper and lower limb heavy resistance training on the peak power, throwing velocity, and sprint performance of elite male handball players. J Strength Cond Res 2011; 25(9): 2424-33. [http://dx.doi.org/10.1519/JSC.0b013e3182030edb]
21869628

[2] Hori N, Newton RU, Andrews WA, Kawamori N, McGuigan MR, Nosaka K. Does performance of hang power clean differentiate performance of jumping, sprinting, and changing of direction? J Strength Cond Res 2008; 22(2): 412-8.

[http://dx.doi.org/10.1519/JSC.0b013e318166052b]

[PMID: 18550955]

[3] Driss T, Vandewalle H, Quièvre J, Miller C, Monod H. Effects of external loading on power output in a squat jump on a force platform: A comparison between strength and power athletes and sedentary individuals. J Sports Sci 2001; 19(2): 99-105.

[http://dx.doi.org/10.1080/026404101300036271] [PMID: 11217015]

[4] Anderson CE, Sforzo GA, Sigg JA. The effects of combining elastic and free weight resistance on strength and power in athletes. J Strength Cond Res 2008; 22(2): 567-74.

[http://dx.doi.org/10.1519/JSC.0b013e3181634d1e]

[PMID: 18550975]

[5] Bozic PR, Bacvarevic BB. Force-velocity profiles of elite athletes tested on a cycle ergometer. Monten J Sports Sci Med 2018; 7(1): 59. [http://dx.doi.org/10.26773/mjssm.180308]

[6] Mosti MP, Carlsen T, Aas E, Hoff J, Stunes AK, Syversen U. Maximal strength training improves bone mineral density and neuromuscular performance in young adult women. J Strength Cond Res 2014; 28(10): 2935-45.

[http://dx.doi.org/10.1519/JSC.0000000000000493]

[PMID: 24736773]

[7] Khosla S, Riggs BL. Pathophysiology of age-related bone loss and osteoporosis. Endocrinol Metab Clin North Am 2005; 34(4): 1015-1030, xi.

[http://dx.doi.org/10.1016/j.ecl.2005.07.009] [PMID: 16310636]

[8] Bouxsein ML, Marcus R. Overview of exercise and bone mass. Rheum Dis Clin North Am 1994; 20(3): 787-802.

[http://dx.doi.org/10.1016/S0889-857X(21)00361-6] [PMID: 7984790]

[9] Yuan Y, Chen X, Zhang L, et al. The roles of exercise in bone remodeling and in prevention and treatment of osteoporosis. Prog Biophys Mol Biol 2016; 122(2): 122-30.

[http://dx.doi.org/10.1016/j.pbiomolbio.2015.11.005] [PMID: 26657214]

[10] Marques EA, Mota J, Machado L, et al. Multicomponent training program with weight-bearing exercises elicits favorable bone density, muscle strength, and balance adaptations in older women. Calcif Tissue Int 2011; 88(2): 117-29.

[http://dx.doi.org/10.1007/s00223-010-9437-1] [PMID: 21113584]

[11] Shah K, Armamento-Villareal R, Parimi N, et al. Exercise training in obese older adults prevents increase in bone turnover and attenuates decrease in hip bone mineral density induced by weight loss despite decline in bone-active hormones. J Bone Miner Res 2011; 26(12): 2851-9.

[http://dx.doi.org/10.1002/jbmr.475] [PMID: 21786319]

[12] Bolam KA, van Uffelen JG, Taaffe DR. The effect of physical exercise on bone density in middle-aged and older men: A systematic review. Osteoporos Int 2013; 24(11): 2749-62.

[http://dx.doi.org/10.1007/s00198-013-2346-1] [PMID: 23552825]

[13] Lind M, Deleuran B, Thestrup-Pedersen K, Søballe K, Eriksen EF, Bünger C. Chemotaxis of human osteoblasts. Effects of osteotropic growth factors. Acta Pathol Microbiol Scand Suppl 1995; 103(2): 140-6.

[http://dx.doi.org/10.1111/j.1699-0463.1995.tb01089.x] [PMID: 7748538]

[14] Snow-Harter CM. Bone health and prevention of osteoporosis in active and athletic women. Clin Sports Med 1994; 13(2): 389-404. [http://dx.doi.org/10.1016/S0278-5919(20)30337-9] [PMID: 8013040]

[15] Davee AM, Rosen CJ, Adler RA. Exercise patterns and trabecular bone density in college women. J Bone Miner Res 1990; 5(3): 245-50. [http://dx.doi.org/10.1002/jbmr.5650050307] [PMID: 2333783]

[16] Creighton DL, Morgan AL, Boardley D, Brolinson PG. Weightbearing exercise and markers of bone turnover in female athletes. $\mathrm{J}$ Appl Physiol 2001; 90(2): 565-70.

[http://dx.doi.org/10.1152/jappl.2001.90.2.565] [PMID: 11160054]

[17] Cruz-Jentoft AJ, Baeyens JP, Bauer JM, et al. European Working Group on Sarcopenia in Older People. Sarcopenia: European consensus on definition and diagnosis: Report of the European Working Group on Sarcopenia in Older People. Age Ageing 2010; 39(4): 412-23.

[http://dx.doi.org/10.1093/ageing/afq034] [PMID: 20392703]

[18] Studenski SA, Peters KW, Alley DE, et al. The FNIH sarcopenia 
project: rationale, study description, conference recommendations, and final estimates. J Gerontol A Biol Sci Med Sci 2014; 69(5): 547-58. [http://dx.doi.org/10.1093/gerona/glu010] [PMID: 24737557]

[19] Belarmino G, Gonzalez MC, Sala P, et al. Diagnosing sarcopenia in male patients with cirrhosis by dual-energy X-Ray absorptiometry estimates of appendicular skeletal muscle mass. JPEN J Parenter Enteral Nutr 2018; 42(1): 24-36.

[http://dx.doi.org/10.1177/0148607117701400] [PMID: 28402708]

[20] Garner DM, Garfinkel PE. The Eating Attitudes Test: An index of the symptoms of anorexia nervosa. Psychol Med 1979; 9(2): 273-9. [http://dx.doi.org/10.1017/S0033291700030762] [PMID: 472072]

[21] FAO. W; Energy, UNU Proteins requirements in technical report Series 724. Geneva: World Health Organization 1985; pp. 1-110.

[22] Food US, Board N. Recommended dietary allowances. National Research Council Report and Circular SeriesNational Academy of Sciences 1989; p. 115.

[23] Espallargues M, Sampietro-Colom L, Estrada MD, et al. Identifying bone-mass-related risk factors for fracture to guide bone densitometry measurements: A systematic review of the literature. Osteoporos Int 2001; 12(10): 811-22.

[http://dx.doi.org/10.1007/s001980170031] [PMID: 11716183]

[24] Rauch F, Bailey DA, Baxter-Jones A, Mirwald R, Faulkner R. The 'muscle-bone unit' during the pubertal growth spurt. Bone 2004; 34(5): 771-5.

[http://dx.doi.org/10.1016/j.bone.2004.01.022] [PMID: 15121007]

[25] Wang MC, Bachrach LK, Van Loan M, Hudes M, Flegal KM, Crawford $\mathrm{PB}$. The relative contributions of lean tissue mass and fat mass to bone density in young women. Bone 2005; 37(4): 474-81.

[http://dx.doi.org/10.1016/j.bone.2005.04.038] [PMID: 16040285]

[26] Chon SJ, Koh YK, Heo JY, et al. Effects of vitamin D deficiency and daily calcium intake on bone mineral density and osteoporosis in Korean postmenopausal woman. Obstet Gynecol Sci 2017; 60(1): 53-62.

[http://dx.doi.org/10.5468/ogs.2017.60.1.53] [PMID: 28217672]

[27] Ross AC, Manson JE, Abrams SA, et al. The 2011 report on dietary reference intakes for calcium and vitamin D from the Institute of Medicine: what clinicians need to know. J Clin Endocrinol Metab 2011; 96(1): 53-8.

[http://dx.doi.org/10.1210/jc.2010-2704] [PMID: 21118827]

[28] Teegarden D, Lyle RM, McCabe GP, et al. Dietary calcium, protein, and phosphorus are related to bone mineral density and content in young women. Am J Clin Nutr 1998; 68(3): 749-54.

[http://dx.doi.org/10.1093/ajcn/68.3.749] [PMID: 9734757]

[29] Tuero BB, Mena Valverde MC, Vega MF, Vizuete AA, López Sobaler $\mathrm{AM}$, Ortega Anta RM. Influence of calcium and phosphorus intake on bone mineral density in young women. Arch Latinoam Nutr 2004; 54 : 203-8.

[30] Cappozzo A, Felici F, Figura F, Gazzani F. Lumbar spine loading during half-squat exercises. Med Sci Sports Exerc 1985; 17(5): 613-20.

[http://dx.doi.org/10.1249/00005768-198510000-00016] [PMID: 4068969]

[31] Gullberg B, Johnell O, Kanis JA. World-wide projections for hip fracture. Osteoporos Int 1997; 7(5): 407-13. [http://dx.doi.org/10.1007/PL00004148] [PMID: 9425497]

[32] Cummings SR, Melton LJ. Epidemiology and outcomes of osteoporotic fractures. Lancet 2002; 359(9319): 1761-7. [http://dx.doi.org/10.1016/S0140-6736(02)08657-9] 12049882]

[33] Cooper C, Cole ZA, Holroyd CR, et al. IOF CSA Working Group on Fracture Epidemiology. Secular trends in the incidence of hip and other osteoporotic fractures. Osteoporos Int 2011; 22(5): 1277-88. [http://dx.doi.org/10.1007/s00198-011-1601-6] [PMID: 21461721]

[34] Greenlund LJ, Nair KS. Sarcopenia--consequences, mechanisms, and potential therapies. Mech Ageing Dev 2003; 124(3): 287-99. [http://dx.doi.org/10.1016/S0047-6374(02)00196-3] 12663126]

[35] Ferrer Cañabate J, Tovar Zapata I, Tortosa Oltra J, Martínez Hernández P. Biochemical markers of remodeling in the study of bone mass in newly menopausal women without osteoporosis. Med Clin (Barc) 2005; 124(7): 241-9.

[http://dx.doi.org/10.1157/13072034] [PMID: 15743588]

[36] Janckila AJ, Takahashi K, Sun SZ, Yam LT. Tartrate-resistant acid phosphatase isoform $5 \mathrm{~b}$ as serum marker for osteoclastic activity. Clin Chem 2001; 47(1): 74-80.

[http://dx.doi.org/10.1093/clinchem/47.1.74] [PMID: 11148180]

[37] Matsumoto T, Nakagawa S, Nishida S, Hirota R. Bone density and bone metabolic markers in active collegiate athletes: Findings in longdistance runners, judoists, and swimmers. Int J Sports Med 1997; 18(6): 408-12.

[http://dx.doi.org/10.1055/s-2007-972656] [PMID: 9351685]

[38] Keul J, Doll E, Keppler D. Energy metabolism of human muscle. Med sport 1972; 7: I-XI.

[http://dx.doi.org/10.1159/000393324]

[39] Montero FJC, Peinado PJB, Meléndez-Ortega A, Gross MG. Control biológico del entrenamiento de Resistencia (Biological control of endurance training). RICYDE. Rev Int Cienc Deporte 2006; 2(2): 65-87.

[http://dx.doi.org/10.5232/ricyde2006.00205]

[40] Chevion S, Moran DS, Heled Y, et al. Plasma antioxidant status and cell injury after severe physical exercise. Proc Natl Acad Sci USA 2003; 100(9): 5119-23.

[http://dx.doi.org/10.1073/pnas.0831097100] [PMID: 12702774]

[41] Bär PR, Amelink GJ, Oldenburg B, Blankenstein MA. Prevention of exercise-induced muscle membrane damage by oestradiol. Life Sci 1988; 42(26): 2677-81.

[http://dx.doi.org/10.1016/0024-3205(88)90243-3] [PMID: 3386407]

[42] Koskinen SOA, Höyhtyä M, Turpeenniemi-Hujanen T, et al. Serum concentrations of collagen degrading enzymes and their inhibitors after downhill running. Scand J Med Sci Sports 2001; 11(1): 9-15. [http://dx.doi.org/10.1034/j.1600-0838.2001.011001009.x] [PMID: 11169229]

[43] Stupka N, Tarnopolsky MA, Yardley NJ, Phillips SM. Cellular adaptation to repeated eccentric exercise-induced muscle damage. J Appl Physiol 2001; 91(4): 1669-78.

[http://dx.doi.org/10.1152/jappl.2001.91.4.1669] [PMID: 11568149]

\section{2021 Reyes et al.}

This is an open access article distributed under the terms of the Creative Commons Attribution 4.0 International Public License (CC-BY 4.0), a copy of which is available at: https://creativecommons.org/licenses/by/4.0/legalcode. This license permits unrestricted use, distribution, and reproduction in any medium, provided the original author and source are credited. 